Chapter 5

\title{
Discussions and Policy Implications
}

October 2014

This chapter should be cited as

ERIA (2013), 'Discussions and Policy Implications', in Kutani, I. (ed.), Study on the Development of an Energy Security Index and an Assessment of Energy Security Policy for East Asian Countries. ERIA Research Project Report 2013-24, pp.79-89. Available at: http:/www.eria.org/RPR_FY2013_No.24_Chapter_5.pdf 


\section{CHAPTER 5 \\ Discussions and Policy Implications}

\section{Discussions}

In this study, self-sufficiency rate, diversity of total primary energy supply (TPES) and power generation, energy efficiency, and carbon dioxide $\left(\mathrm{CO}_{2}\right)$ emission were selected as the primary index. An assessment was then conducted to find out the changes that the index could undergo in the future.

\section{Worsening trend in self-sufficiency}

The first observation obtained from this assessment is that self-sufficiency performance is expected to worsen in many countries in the East Asia Summit (EAS) region, with some exceptions. This trend is also observed in countries that are currently energy exporters, such as Brunei, Indonesia, and Malaysia. In particular, non- Organisation for Economic Co-operation and Development (OECD) countries are expected to continue experiencing a high level of economic growth in the future, and consequently, energy demand is forecast to grow steadily. Under such circumstances, there would naturally be limitations to the extent to which countries can maintain a high rate of selfsufficiency.

The rise in import dependency contributes to greater vulnerability in energy security. What can be done to keep such risks from mounting, or to suppress these risks? The first thing that should be done is to develop fossil fuel resources available domestically as far as possible, within economically rational limits. The reason for this is the strong possibility that fossil fuels may continue to be the main energy source for the time range leading up to 2035 that this study analysed, if energy density level and supply stability were to be considered.. 
Another important measure that should be taken is the expansion of the use of renewable energy, beginning with hydropower. For hydropower, there is still ample room for significant development in areas such as parts of the Mekong River Basin. Among the numerous renewable energy, small hydropower is also expected to provide stable output at a low cost. Biomass and geothermal are also attractive energy sources in areas where they are available for use. Other energy sources such as solar and wind are still under consideration in view of the need to achieve a balance with economic viability.

In countries with high levels of energy demand, nuclear is also one of the possible choices. While safety considerations are one of the most important premises in utilising nuclear, nuclear is an attractive option if countries were to consider factors such as the low import risks, high energy supply volume and density, and low levels of air pollutant emissions including $\mathrm{CO}_{2}$ emissions.

Even if various measures such as the aforementioned are implemented, it is not an easy task to achieve a $100 \%$ self-sufficiency rate. If it becomes unavoidable to import energy, regardless of how low the import volumes are, it would then be important to put in place measures aimed at reducing import risks. In short, these measures would focus on the keyword "diversification."

First, there is a need to diversify energy sources that are used. In the 1970s, approximately $75 \%$ of Japan's energy supply was dependent on oil. For that reason, the country suffered significant economic setbacks during the two oil crises that struck in the 1970s. While there are no energy sources with zero risks, it is vital to ensure that the risks accompanying each energy source are not excessive. This can be achieved by combining energy sources that come with different forms of risks.

Second, it is important to ensure the "diversification" of partner countries involved in the import of energy. The degree of risks that accompany each import source country need to be considered. For example, in a situation where the import source country is a stable country in all aspects including politics, economy, and culture; is not engaged in any bilateral conflict; and is highly likely to remain a stable ally over the long-term, the risks would not be significant. On the other hand, if the import partner were a country with 
unstable domestic politics, or is in a situation where the country may become unstable in the near future, there would be significant risks in relying on that country for imports.

Third, it is also important to prepare for the possibility of supply disruptions. Energy is an indispensable element in maintaining the life of citizens, economic activity, and society. As such, energy supply cannot be disrupted even momentarily. However, even in the past few years, events such as the Russia-Ukraine conflict and the Arab Spring have caused delays in the export of natural gas and crude oil. These experiences show that sudden disruption in the flow of energy imports is entirely possible as a result of unforeseen circumstances. Under such circumstances, it is vital to conduct a full review into how countries can secure alternative energy suppliers, and to undertake necessary preparations. One of these methods is to maintain oil stocks. Another method is to conclude agreements with neighbouring countries that provide for flexible arrangements on complementing energy supplies during times of emergency. Alternatively, it is also possible to arrange with the energy exporter for the supply of larger volumes than agreed upon during times of emergency. In considering the various methods available, it is important to put in place measures to maintain a stable energy supply to the country at the lowest cost possible.

Finally, it is important to implement demand-side measures. While all of the aforementioned have been supply-side measures, it is also important to reduce energy consumption itself in order to improve energy security. It is relatively easier to implement measures and obtain results in the industrial sector particularly in sectors that are exposed to international competition. In these sectors, the reduction of manufacturing costs, including energy costs, is directly related to the competitiveness of the company. As such, the motivation to improve energy conservation/efficiency functions naturally in companies. Conversely, in the commercial or residential sector where the scale of energy costs is difficult to visualise, or in situations where the energy bills are set at low levels as a result of subsidies and other policies, it becomes difficult to promote energy-saving measures. Changing the mindset of each individual consumer is an important element in promoting energy conservation/efficiency; however, it is also important to provide an economic incentive for energy-saving campaigns to succeed. 


\section{Mixed view for TPES/power generation diversity}

Different trends can be observed in different countries when it comes to the diversity of TPES and power generation.

The first of these trends is characterised by Australia and New Zealand, with policies arising from or as a result of the impact of climate change. In response to the issue of climate change, Australia has been moving toward the use of natural gas, while New Zealand has achieved progress in utilising geothermal energy. These moves are effective in reducing the $\mathrm{CO}_{2}$ emissions. On the other hand, as these measures increase the countries' dependence on a specific energy source, the result is a perceived worsening of the situation, as shown in the indicators that show "Diversity." What must be noted here is the fact that Australia is a producer of natural gas, while New Zealand is a producer of geothermal. "Diversification" signifies a diversity in the country's dependence on imports. In this sense, both countries need not be overly concerned about the "worse off" situation of their "Diversification" indicators when placed against this background.

Japan's "Diversification" indicators have also been assessed to be worse off. The reason is the expected fall in the nuclear generation output. It could be described as a clear example of a situation that is a direct reflection of policy changes. Although Japan has achieved progress in diversifying its energy source over the past 30 years, it has now arrived at the watershed of that policy. To Japan, which depends on imports for the larger part of its energy supply, nuclear is an important tool toward realising the diversification of its energy sources. The choice of whether or not to make use of nuclear is an important element that can determine the state of energy security in Japan in the future.

Despite a gradual increase in diversity among many countries, dramatic improvements have not been observed. The use of rich energy supplies produced by the country, or the use of cheap energy sources, are rational choices from the perspective of energy security and economic viability. For that reason, it is not easy to change the high level of dependence that Laos has on hydropower, or that Viet Nam has on coal, just to name a few examples. Furthermore, energy supply and power plants typically enjoy long service life 
spans. This makes it difficult to change energy utilisation methods in the short term.

\section{Improvements in the energy efficiency}

For most countries, energy efficiency is expected to improve going forward. One of the factors behind this is the increase in the proportion of high valueadded industries resulting from changes in industrial structure. While it may be difficult to reduce TPES amidst a situation of growing population and economic growth, it is nevertheless possible to improve energy efficiency. By sustaining such measures, it may be possible to dampen the rise in energy demand, or in other words, to suppress the increase in the volume of energy imports.

\section{$\mathrm{CO}_{2}$ emission reduction}

The quantity of $\mathrm{CO}_{2}$ emissions takes on different aspects depending on the indicators that are used to assess emissions. While it is difficult to reduce TPES, except in some countries, an increase in the amount of $\mathrm{CO}_{2}$ emissions would be inevitable based on the premise of the current energy supply structure, which focuses on fossil fuels. Tackling the climate change is a common issue shared by countries around the world, and no country can avoid taking its part of that responsibility. What needs to be done in this respect is to increase the use of low-carbon energy as far as possible, and to improve the energy efficiency as far as possible.

Among fossil fuels, low-carbon energy refers to oil rather than coal, and natural gas rather than oil. Nuclear and renewable energy are options that are even cleaner than fossil fuels. As earlier explained, each energy source has its own merits and demerits, and there are varied ways of combining these energy sources. Each country has the authority to decide on what kind of energy mix it may wish to achieve; however, it is vital to take into consideration the issue of climate change in such discussions and debates.

The energy efficiency has already been discussed in the previous section. If energy were used in a highly efficient manner, it would be possible to 
minimise the amount of fossil fuels consumed, and thereby contribute to reducing $\mathrm{CO}_{2}$ emissions.

\section{Effect of an APS scenario}

In estimating future ESIs, the alternative policy scenario (APS) scenario, which projects further improvements in energy efficiency, has been adopted in addition to the business-as-usual (BAU) scenario. This takes into account policy measures and technological innovation, and can be considered as additional measures to the existing system being employed in various fields.

Many ESIs perform better in future scenarios presented by APS scenario rather than by BAU scenario. That is to say, the various energy efficiency policies established hypothetically under an APS scenario are believed to be able to contribute to improvements in energy security. Accordingly, countries can use the future scenarios presented by the APS scenario as a point of reference in considering future policies for the countries.

\section{Policy Implications}

\section{Effectiveness of ESI}

In this study, the past three years were spent gaining a quantitative understanding of the energy security situation, analysing the results, and developing ESIs. In the 2012 research, the study concluded that there was a correlation between ESIs and policies. Consequently, the study found that the ESIs developed as part of this research is an effective tool in measuring the status of energy security. While no one can deny the importance of energy security, there are few methods that can be used to obtain an accurate grasp of the situation. Although ESIs are restricted by the available data and by other factors, these can be useful in providing policymakers with a quantitative grasp of the energy security situation. By harnessing this in an effective manner, it would be possible to uncover the energy security flaws of a country, or to assess the effects of policies implemented in the past. The ability to carry out such work would facilitate a more accurate grasp of the 
environment surrounding the country, and lead to the formulation of new policies.

However, caution must also be taken in using ESIs. The individual indicators present a part of the overall energy security situation, and the numbers themselves do not lie. Nevertheless, changes in the statistics are backed by many underlying factors, so there is a need to exercise prudence in interpreting the numbers. One of the examples that we can use here is the aforementioned expansion in the use of geothermal in New Zealand. While this policy contributes to a worsened situation in the performance of indicators that show "Diversification," it also contributes to improvements in indicators that show "Self-sufficiency" and " $\mathrm{CO}_{2}$ emissions." Depending on the situation that a country finds itself in, the focus would be placed on different indicators. Hence, even while taking note or referring to these ESIs, it is important to explore the direction that the country should take in considering its own situation, and to formulate the necessary policies accordingly.

A second key point would be to periodically reevaluate ESIs, and to feed these changes back into policies. The various cross-sections of energy security shown by ESIs cannot change over the short term of, for instance, one or two years. For example, after the oil crises in the 1970s, Japan took an extremely long time of 20 to 30 years before it arrived at the energy mix it was using before the great East Japan earthquake. This means that long periods of time are required for certain policies to penetrate society, and to actually change the energy supply structure. Hence, short-term changes that take place over one or two years should not be traced using ESIs. Rather, ESIs should be used to evaluate changes in units of 5 or 10 years, and the necessary reviews and revisions carried out based on these assessments.

\section{Possible options for energy mix}

Based on analyses conducted using ESIs, what are the specific recommendations that can be raised with the aim of improving regional energy security? 
One of the possible recommendations is related to energy supply and power generation mix. A direction that countries should aim toward in the long term could be achieving a mixture of coal and renewables, or with nuclear.

From the perspective of the self-sufficiency rate, apart from the fact that renewable energy and nuclear are domestically produced energy sources, there are relatively rich coal resources in the EAS region. This means that expanding the use of coal can contribute to improving the self-sufficiency rate for many countries. Even if the country does not possess any coal resources, it faces little risk in importing coal from countries within the same EAS region as they share common interests. This would be safer than increasing oil usage, for example, which would leave the country no choice but to be dependent on the Middle East.

In this study, the importance of diversifying energy sources has been repeatedly pointed out. However, as the need for diversification is based on the premise of a high level of import dependency, if a combination of coal with renewable energy or nuclear can contribute to improving the selfsufficiency rate, then greater dependence on these forms of energy would not pose any problems.

From the perspective of economic viability, it is needless to state that coal has more advantages in comparison with other fossil fuels. On nuclear, as in the case of Japan, even though a large reserve fund has been allocated in preparation for a large-scale accident, nuclear remains highly competitive today as compared to oil-fired thermal power, solar, and wind. Costs vary significantly depending on the type of renewable energy. At this point in time, hydropower, geothermal, and biomass are good choices of energy source.

The emission of $\mathrm{CO}_{2}$ and air pollutants is a problem caused by the use of coal. Thus, in addition to using coal in the most efficient manner possible, it is also necessary to introduce an adequate amount of renewable energy and nuclear in order to offset the incremental emissions of $\mathrm{CO}_{2}$ and other substances that arise from the use of coal. 
As generally observed, the combination of coal and renewable energy or nuclear is typically perceived as being able to contribute to energy security in many ways. However, its viability should be assessed on a country-bycountry basis. For example, since Myanmar has rich resources of natural gas and hydropower, the combination of coal with either option is suitable for the country, and it would be practical to use coal partially for the purpose of risk diversification. In the case of Thailand, opposition from citizens makes it extremely difficult to develop new coal-fired thermal power plants, so it would be more practical for the country to opt for a mix that focuses on the use of natural gas.

Another point that should be considered is the time line. Expanding the use of coal can be achieved over a relatively shorter period of time, but it would require a longer lead-time to increase the use of renewable energy or nuclear to a sufficient extent. In the case of nuclear, it is necessary to first have a certain scale of demand, and to undergo a process of winning over the consensus of the citizens. As such, the number of countries that can adopt nuclear may be limited. Hence, in the short to medium term, it would be more practical to diversify risks by using natural gas while focusing on strengthening the use of renewable energy and enhancing the efficiency of coal-fired thermal power generation.

To achieve such changes in energy mix, it is important to formulate plans with a long-term perspective, and to have strong political and administrative will in order to bring the plans to fruition.

\section{Importance of regional approach}

Another point that should be raised is the importance and meaning of regional cooperation. Figure 5-1 uses the example of the ASEAN to illustrate the mix of TPES. As shown in the figure, despite significant imbalance and variations in energy sources used by each country, the overall picture for ASEAN as a region is a relatively balanced one.

The same trend is observed for the European Union (EU). The EU is a collective of countries of various sizes, from large to small, with significant variances in their respective energy sources. From the perspective of energy 
security, this may not be an ideal situation. However, the EU is a collective of countries that share interests, and the Union itself is well balanced. That is to say, it has an energy supply structure with risks that are diversified. In other words, countries belonging to the EU can achieve a level of energy security through regional cooperation that they would never be able to achieve independently.

Similarly, the ASEAN is a collective of countries that share common interests, and is also a group premised on mutual interdependence. Based on this premise, it would be possible to build an even stronger energy security system. It would be even more ideal if this system could be expanded to include the EAS framework.

Oftentimes, energy security is established in the unit of a single country. Mutual distrust between countries lies at the root of this trend. EAS countries, which are also located in Asia, are positioned in an environment that allows them to share interests easily. By eliminating the distrust among countries and considering matters and issues as a region, it would then become possible to strengthen energy security. Conversely, it would also be possible to achieve the effect of improving and strengthening relationships of trust between EAS countries by strengthening mutual interdependence with the aim of improving energy security.

\section{Figure 5-1: Primary Energy Supply Mix (2006-2010)}

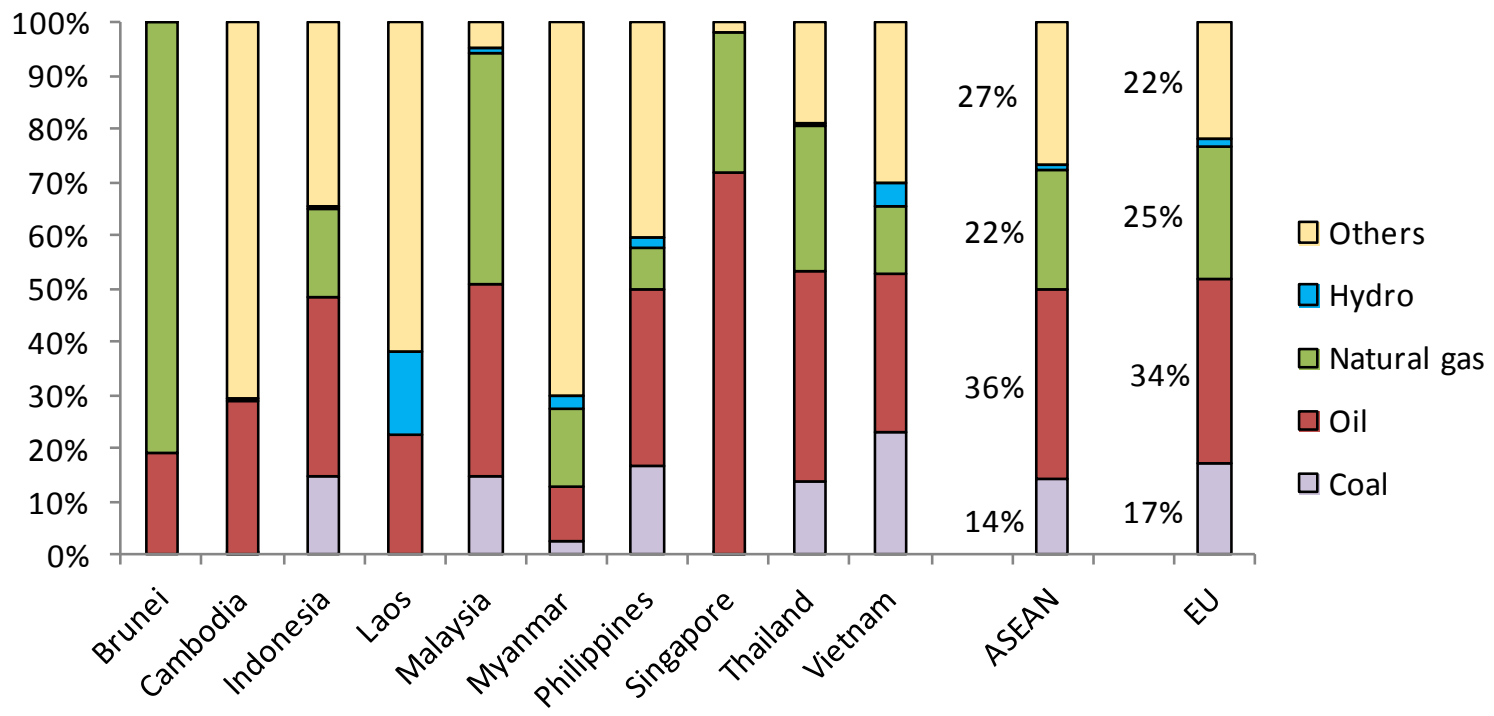

Source: International Energy Agency (2013), Energy Balance, 2013. Laos. 
As shown through this study, policy assessments using ESIs can contribute, even in small ways, to changes in the practical world, and to strengthening regional energy security. 